\title{
A new model for biomineralization and trace-element signatures of Foraminifera tests
}

\author{
G. Nehrke ${ }^{1}$, N. Keul ${ }^{2}$, G. Langer ${ }^{3}$, L. J. de Nooijer ${ }^{4}$, J. Bijma ${ }^{1}$, and A. Meibom ${ }^{5}$ \\ ${ }^{1}$ Alfred Wegener Institute, Bremerhaven, Germany \\ ${ }^{2}$ Lamont-Doherty Earth Observatory, Columbia University, Palisades, New York, USA \\ ${ }^{3}$ Department of Earth Sciences, Cambridge University, Cambridge, UK \\ ${ }^{4}$ Department of Marine Geology, Royal Netherlands Institute of Sea Research, Horntje, the Netherlands \\ ${ }^{5}$ Laboratory for Biological Geochemistry, School of Architecture, Civil and Environmental Engineering (ENAC), Ecole \\ Polytechnique Fédérale de Lausanne, 1015 Lausanne, Switzerland
}

Correspondence to: G. Nehrke (gernot.nehrke@awi.de) and A. Meibom (anders.meibom@epfl.ch)

Received: 27 May 2013 - Published in Biogeosciences Discuss.: 18 June 2013

Revised: 24 September 2013 - Accepted: 24 September 2013 - Published: 29 October 2013

\begin{abstract}
The $\mathrm{Mg} / \mathrm{Ca}$ ratio of Foraminifera calcium carbonate tests is used as proxy for seawater temperature and widely applied to reconstruct global paleo-climatic changes. However, the mechanisms involved in the carbonate biomineralization process are poorly understood. The current paradigm holds that calcium ions for the test are supplied primarily by endocytosis of seawater. Here, we combine confocal-laser scanning-microscopy observations of a membrane-impermeable fluorescent marker in the extant benthic species Ammonia aomoriensis with dynamic ${ }^{44} \mathrm{Ca}-$ labeling and NanoSIMS isotopic imaging of its test. We infer that $\mathrm{Ca}$ for the test in A. aomoriensis is supplied primarily via trans-membrane transport, but that a small component of passively transported (e.g., by endocytosis) seawater to the site of calcification plays a key role in defining the trace-element composition of the test. Our model accounts for the full range of $\mathrm{Mg} / \mathrm{Ca}$ and $\mathrm{Sr} / \mathrm{Ca}$ observed for benthic Foraminifera tests and predicts the effect of changing seawater $\mathrm{Mg} / \mathrm{Ca}$ ratio. This places foram-based paleoclimatology into a strong conceptual framework.
\end{abstract}

\section{Introduction}

Calcium carbonate tests (shells) formed by unicellular Foraminifera are present in marine sedimentary records since the Ordovician $(\sim 290$ million years ago) (Martin, 1995; Schallreuter, 1983). With different species adapted to specific environmental conditions, their relative taxonomic abundances as well as the elemental (e.g., $\mathrm{Mg} / \mathrm{Ca}$ ) and isotopic (e.g., $\delta^{18} \mathrm{O}$ ) composition of their tests are frequently used to reconstruct global climate change associated with, for example, glacial-interglacial cycles (Elderfield and Ganssen, 2000) and mass extinctions (Kiessling et al., 2008). However, the use of Foraminifera tests as paleo-environmental archives is complicated by biological processes, which cause their chemical and isotopic compositions to be significantly different from $\mathrm{Ca}$ carbonates precipitated inorganically under the same environmental conditions. These differences are referred to as the "vital effect" (Urey et al., 1951). A better understanding of the Foraminifera biomineralization process is essential to the identification of the mechanism(s) responsible for such chemical and isotopic fractionations. One fundamental question in this regard is how the constituents of the tests, especially the dominant cation $\mathrm{Ca}^{2+}$ and the minor/trace elements $\mathrm{Mg}$ and $\mathrm{Sr}$, are transported from the ambient seawater to the site of calcification.

A widely accepted model holds that endocytosis of seawater is the principal mechanism involved in test formation: special vesicles transport seawater to the site of calcification (Erez, 2003; Bentov et al., 2009). This model is based on the key observation that labeling of seawater with the membrane-impermeable fluorescent marker FITC$\mathrm{D}$ (fluorescein isothiocyanate-dextran) results in staining of newly formed chambers in previously decalcified benthic Foraminifera Amphistegina lobifera. This observation led 
to the conclusion that endocytosed seawater is the primary source of ions for calcification. However, the endocytosis model suffers from two problems.

First, a mechanism for the modification of the elemental composition of the vacuolized seawater, in particular Mg removal, during transport to the site of calcification has to be postulated in order to explain the chemical composition of the tests (Erez, 2003).

Secondly, the endocytosis model is challenged by a calculation of the volume of seawater needed to supply the required $\mathrm{Ca}$ to the site of calcification. For the ubiquitous benthic species Ammonia tepida, this is about 75 times the volume of the Foraminifera itself (de Nooijer et al., 2009), assuming initial seawater composition in the vesicles. De Nooijer and co-workers (de Nooijer et al., 2009) did observe seawater endocytosis in A. tepida using the FITC-D marker, but the low vesicle activity observed during normal calcification renders endocytosis insufficient as the major transport mechanism for $\mathrm{Ca}$ from seawater to the site of calcification. To overcome this problem, an internal Ca pool was hypothesized for A. tepida (de Nooijer et al., 2009), but never experimentally demonstrated. (It should be noted that in some studies we cite (de Nooijer et al., 2009; Dissard et al., 2010), the authors have misidentified the species investigated as Ammonia tepida, which actually was Ammonia aomoriensis T6 (the species also used in the present study) (Schweizer et al., 2011; Hayward et al., 2004).)

Nonetheless, it is important to emphasize that endocytosis, or vacuolization of seawater in Foraminifera, is an observed fact, which allows FITC-D to be transported to the site of calcification and, as will become apparent below, does play an important role for the trace-element composition of the test.

Here we use the fluorescent marker FITC-D together with confocal-laser scanning microscopy, and ${ }^{44} \mathrm{Ca}$ pulse-chase experiments in combination with NanoSIMS isotopic imaging to investigate the hypothesis of an intracellular calcium pool in A. aomoriensis. (For details on sample collection, culturing, and incubation conditions, see Appendix) Incubation experiments with FITC-D were performed prior to, during, and after chamber formation to visualize and relate seawater vacuolization to calcification (i.e., formation of new chambers). Formation of a new chamber in A. aomoriensis starts with an organic sheet, onto which calcitic $\mathrm{CaCO}_{3}$ nucleates. In our incubated specimens, chamber formation takes 3-5 h, after which the animal resumes movement and extends its pseudopodial network.

\section{Results}

We did not observe an increased abundance of vesicles prior to chamber formation (Fig. 1a). Moreover, vesicle activity was very low during chamber formation (Fig. 1c). Our results (Fig. 1) confirm the vacuolization of seawater as described

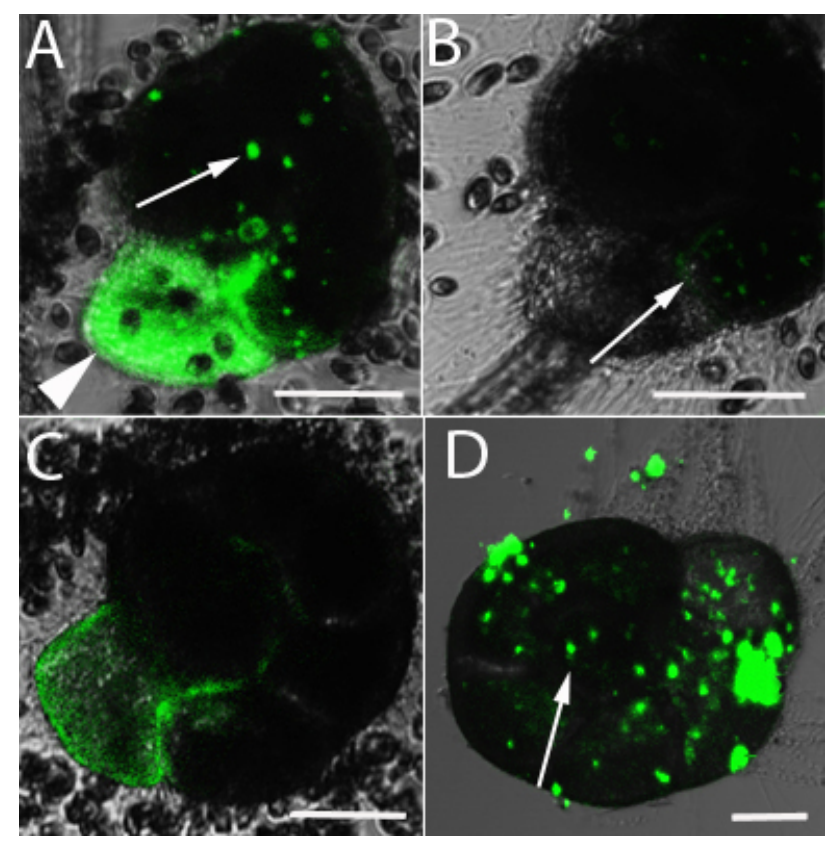

Fig. 1. Laser scanning confocal micrographs of three A. aomoriensis specimens after incubation in FITC-D-labeled seawater. (A) Specimen 1 was incubated in FITC-D labeled seawater for $3.5 \mathrm{~h}$ prior to chamber formation. Immediately after the onset of chamber formation, the FITC-D was removed (see supporting information) and the image taken. Vesicles (ca. 20) were observed inside the cell (arrow). Due to remaining FITC-D-labeled seawater, which could not be washed out, fluorescence is seen inside the newly forming chamber (arrow head). This fluorescence diffuses out of the chamber within $15 \mathrm{~min}$. (B) Image of specimen 1 two hours after the first image (A) was taken. Chamber formation is almost completed. A few small vesicles are still present (arrow). (C) Image of specimen 2 immediately after chamber formation. Specimen 2 was incubated in FITC-D-labeled seawater during chamber formation. No vesicles are present. The new chamber is fluorescent. Note the difference between the fluorescence of the new chamber in (A) caused by remaining FITC-D-labeled seawater that diffused out within 15 min and (C) due to FITC-D incorporated into the newly formed chamber. (D) Image of specimen 3 four hours after FITC-D incubation showing the highest number of vesicles (arrow) observed in this study. Before incubation the specimen was not fed for $48 \mathrm{~h}$. Scale bars are $40 \mu \mathrm{m}$.

by de Nooijer et al. (2009), but a systematic investigation of 20 specimens prior to, during, and after chamber formation revealed a maximum total vesicle volume of about 0.002 times the volume of the cell at any given point in time. This is about four orders of magnitude smaller than the volume of seawater needed to provide sufficient $\mathrm{Ca}$ for one chamber (de Nooijer et al., 2009), which has important consequences for the internal Ca-pool hypothesis.

In the juvenile A. aomoriensis specimens studied here, chamber formation takes place every $24 \mathrm{~h}$. Thus, in order to store internally enough $\mathrm{Ca}$ for the formation of one chamber, 
the seawater-containing vesicles would have to be replenished and the $\mathrm{Ca}$ extracted and stored about $10^{4}$ times per day (i.e., about once every $10 \mathrm{~s}$ ). Confocal microscopy observations rule out such fast vesicle turnover. Thus, we infer that seawater endocytosis and subsequent $\mathrm{Ca}$ storage is not likely to be the primary source of $\mathrm{Ca}$ for chamber formation for A. aomoriensis.

In addition to the formation of a new chamber, A. aomoriensis also thickens older parts of the already existing test. It is difficult to determine visually if the thickening of older chambers occurs at the same time as the formation of new chamber. Precisely quantifying the amount of $\mathrm{Ca}$ consumed by the chamber formation process therefore requires additional information.

Pulse-chase experiments were performed in which the culture medium (natural North Sea seawater) was enriched with ${ }^{44} \mathrm{Ca}$ by the addition of ${ }^{44} \mathrm{CaCl}_{2}\left(99 \%{ }^{44} \mathrm{Ca}\right.$, batch no. 210501, Oak Ridge National Labs). The natural abundance of ${ }^{44} \mathrm{Ca}$ is $\sim 2 \%$, and the ${ }^{44} \mathrm{Ca} /{ }^{40} \mathrm{Ca}$ ratio of the seawater can therefore be increased without altering the total $\mathrm{Ca}$ concentration substantially. In this experiment, the ${ }^{44} \mathrm{Ca} /{ }^{40} \mathrm{Ca}$ ratio was increased by a factor of 5 , while the total $\mathrm{Ca}$ concentration increased only from $\sim 10$ to $\sim 11 \mathrm{mM}$. Calcification by the specimens maintained in this medium did not visually deviate from that observed in unaltered seawater.

In a first experiment (Experiment 1), ${ }^{44} \mathrm{Ca}$ was added to the culture medium of a single specimen of A. aomoriensis. After $12 \mathrm{~h}$, the specimen was transferred to isotopically normal seawater, where chamber formation started after $3 \mathrm{~h}$. In a second experiment (Experiment 2), ${ }^{44} \mathrm{Ca}$ was spiked to the culture medium as soon as chamber formation began. After chamber formation $(\sim 3 \mathrm{~h})$, the experiments were terminated by removing the specimens from the culture media, followed by cleaning with $\mathrm{NaOCl}(5 \%)$ to remove the organics, washing with de-ionized water, and subsequent drying. The samples were then embedded in resin (Araldite, 2020), and polished cross sections were prepared for NanoSIMS analysis (cf. SI). The resulting NanoSIMS images of the ${ }^{44} \mathrm{Ca} /{ }^{40} \mathrm{Ca}$ distribution in the tests are shown in Fig. 2. In these NanoSIMS maps, blue color signifies a natural ${ }^{44} \mathrm{Ca} /{ }^{40} \mathrm{Ca}$ ratio of 0.02 . Yellowish colors signify carbonate added during ${ }^{44} \mathrm{Ca}$ enrichment of the medium, which is enriched in ${ }^{44} \mathrm{Ca}$ by a factor of 5 over the natural ratio, as demonstrated in Fig. A1. From these pulse chase experiments, several important conclusions can be drawn.

Experiment 1 showed that neither the newly formed chamber nor the older parts of the test became enriched in ${ }^{44} \mathrm{Ca}$ (Fig. 2b). Therefore, the formation of a putative $\mathrm{Ca}$ pool would have to take place after the specimen was transferred to normal seawater (i.e., during the $\sim 3 \mathrm{~h}$ prior to the onset of chamber formation). However, the low vesicle activity determined in the FITC-D incubation experiments and the volume considerations presented above strongly argue against such a scenario.

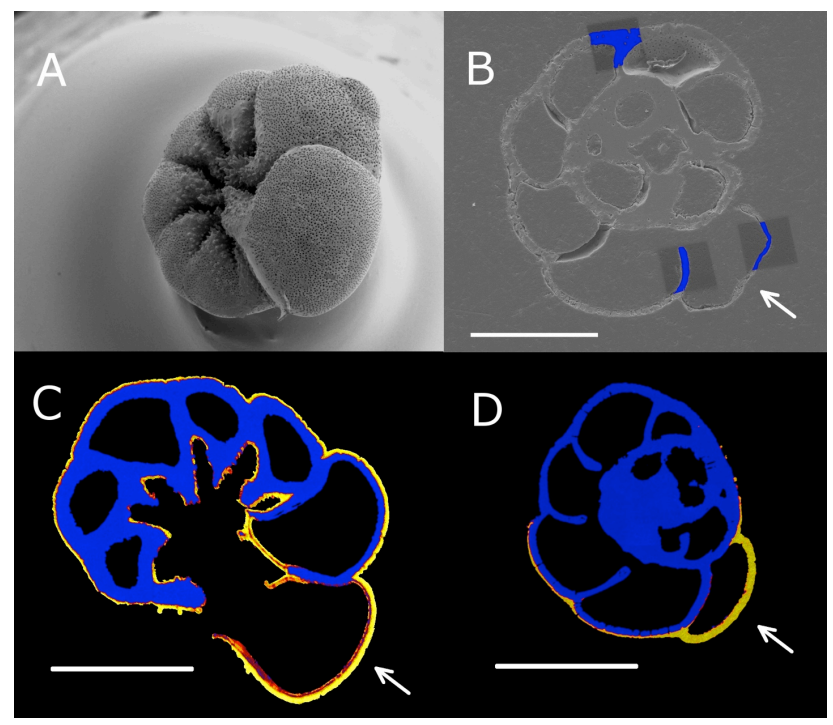

Fig. 2. (A) Scanning electron microscopy (SEM) image of an intact A. aomoriensis test. (B) SEM image of an embedded specimen (cross section) from Experiment 1 , overlain with ${ }^{44} \mathrm{Ca} /{ }^{40} \mathrm{Ca}$ NanoSIMS maps. In these maps, blue areas signify normal ${ }^{44} \mathrm{Ca} /{ }^{40} \mathrm{Ca}$ ratio of 0.02 (cf. Fig. A1). A ${ }^{44} \mathrm{Ca}$ label was added and removed prior to the onset of chamber formation. Absence of ${ }^{44} \mathrm{Ca}$ enrichment in the test indicates absence of an internal Ca pool. (C) and (D) NanoSIMS maps of two embedded specimens from Experiment 2 in cross section. The isotopic label was added at the onset of chamber formation. Blue color signifies a normal ${ }^{44} \mathrm{Ca} /{ }^{40} \mathrm{Ca}$ ratio of 0.02 . Yellowish color indicates enhanced (by a factor of 5 , cf. Fig. A1) ${ }^{44} \mathrm{Ca} /{ }^{40} \mathrm{Ca}$ ratio due to ${ }^{44} \mathrm{Ca}$ enrichment of the seawater. Newly formed chambers indicated by arrows. Scale bar is $100 \mu \mathrm{m}$.

Figure 2c and $d$ show NanoSIMS maps of two Foraminifera tests from Experiment 2. In one Foraminifera the new chamber, the wall between the new and the previous chamber, as well as a layer on the outside of all previously formed chambers of the test are enriched in ${ }^{44} \mathrm{Ca}$ by a factor of 5 (Fig. 2c). In the other Foraminifera, the new chamber and a layer of calcium carbonate added to the two previous chambers were enriched in ${ }^{44} \mathrm{Ca}$ by a factor of 5 (Fig. 2d). This demonstrates that $\mathrm{Ca}$ was transported from the seawater to the site of calcification while the chamber was being formed, during which vacuolization was particularly weak. Transport of $\mathrm{Ca}$ continues throughout the $3 \mathrm{~h}$ period of active test formation as inferred from the fact that the newly formed chambers are enriched in ${ }^{44} \mathrm{Ca}$ throughout. The ${ }^{44} \mathrm{Ca}$-enriched calcite layer added to the outer surface of previously formed chambers decreases in thickness with increasing chamber age (Fig. 2c and d).

From these experiments, it is concluded that uptake of $\mathrm{Ca}$ via seawater endocytosis and transport by vesicles to the site of calcification during chamber formation can be excluded as the primary mechanism for test formation because the observed vesicle activity (Fig. 1) cannot provide enough $\mathrm{Ca}$ to build the test on a $3 \mathrm{~h}$ timescale. Furthermore, 


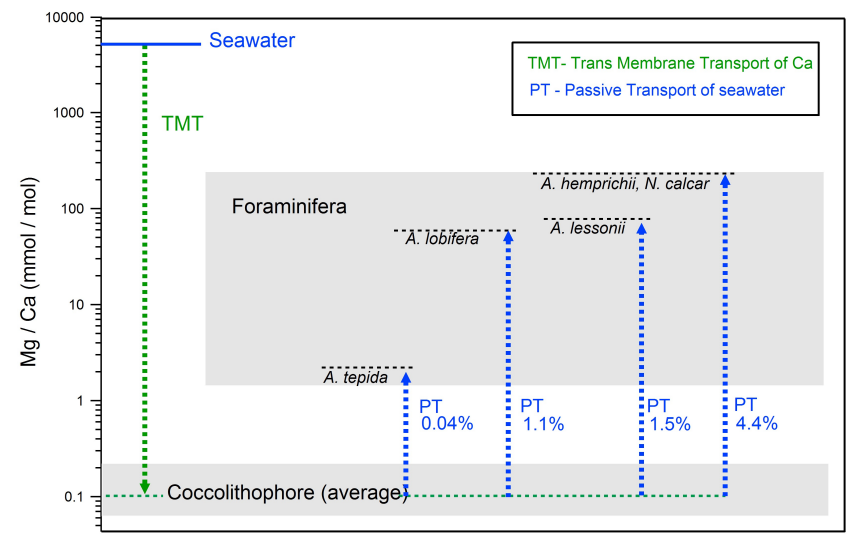

Fig. 3. A new model for trace-element compositions in Foraminifera tests. The full range (grey fields) and the average $\mathrm{Mg} / \mathrm{Ca}$ ratios (hatched lines) are indicated for coccolithophores and for four species of Foraminifera, spanning the entire range of observed $\mathrm{Mg} / \mathrm{Ca}$ ratios (cf. Table A1). See text for discussion.

internal storage of $\mathrm{Ca}$ (i.e., the existence of a $\mathrm{Ca}$ pool) can also be definitively ruled out, and there is therefore no calcification reservoir on which processes such as Rayleigh fractionation operate in the course of test biomineralization (Elderfield et al., 1996).

\section{Discussion}

The only conceivable mechanism left to consider is that $\mathrm{Ca}$ is transported to the site of calcification across the cell membrane. Trans-membrane transport (TMT) is known to occur in other important marine calcifying organisms, in particular coccolithophores, which are unicellular organisms, in which vacuolization has never been observed. Coccolithophores therefore rely only on TMT of $\mathrm{Ca}$ (and $\mathrm{Mg}$ and $\mathrm{Sr}$ ) for the formation of their carbonate tests (Langer et al., 2009, 2006; Gussone et al., 2006).

TMT is generally characterized by strong differences in selectivity for different elements (for details see Langer et al. (2006) and references therein). For example, the discrimination of a typical $\mathrm{Ca}$ channel against $\mathrm{Mg}$ is much stronger than against $\mathrm{Sr}$, because the surface charge density of $\mathrm{Mg}$ is different from that of $\mathrm{Ca}$ and $\mathrm{Sr}$, which are similar (Allen and Sanders, 1994). This is clearly reflected in the trace-element composition of coccolithophores, which are extremely depleted in $\mathrm{Mg}$, with $\mathrm{Mg} / \mathrm{Ca}$ ratios in the range $0.06-0.2 \mathrm{mmol} \mathrm{mol}^{-1}$ (i.e., about 4-5 orders of magnitude lower than the seawater $\mathrm{Mg} / \mathrm{Ca}$ ratio of $\sim 5200 \mathrm{mmol} \mathrm{mol}^{-1}$ (Fig. 3)). Sr/Ca ratios in coccolithophore tests, on the other hand, are around $3 \mathrm{mmol} \mathrm{mol}^{-1}$, only about a factor of 3 lower than the seawater ratio of $8.8 \mathrm{mmol} \mathrm{mol}^{-1}$ and, importantly, very similar to the foraminiferal $\mathrm{Sr} / \mathrm{Ca}$ ratios (Table A2).
However, in any comparison between Foraminifera and coccolithophore trace-element compositions, it is important to keep in mind that the site of calcification within coccolithophores is perfectly sealed from the surrounding seawater, and TMT represents the only pathway for $\mathrm{Ca}, \mathrm{Mg}$ and $\mathrm{Sr}$ transport. In contrast, Foraminifera do vacuolize seawater. Furthermore, the foraminiferal site of calcification is, at least in the species under consideration here, an extracellular space. The vacuolization model (Erez, 2003) assumes that the pseudopodial network, which separates the calcification site from the surrounding seawater, effectively seals off the site of calcification. This assumption must be largely true, because otherwise any control over the biomineralization process would be impossible. However, it is possible that the pseudopodial network is temporarily or permanently leaky, and it is certain that vacuolized seawater (carrying fluorescent FITC-D) reaches the site of calcification. Both pathways would allow seawater with essentially unfractionated element ratios to reach the site of calcite formation.

Together with the experimental evidence presented above, these considerations lead us to propose the following model for Foraminifera test formation and trace-element composition.

Figure 3 shows the $\mathrm{Mg} / \mathrm{Ca}$ ratio of seawater (Pilson, 1998), the range of $\mathrm{Mg} / \mathrm{Ca}$ measured in coccolithophores (with an average of $0.1 \mathrm{mmol} \mathrm{mol}^{-1}$, Blanco-Ameijeiras et al., 2012), and the full range of $\mathrm{Mg} / \mathrm{Ca}$ ratios measured in Foraminifera (Bentov and Erez, 2006; Raja et al., 2005), spanning about two orders of magnitude, from $\sim 2 \mathrm{mmol} \mathrm{mol}^{-1}$ in A. tepida (Dissard et al., 2010) and $\sim 59 \mathrm{mmol} \mathrm{mol}^{-1}$ in A. lobifera (Segev and Erez, 2006), $77 \mathrm{mmol} \mathrm{mol}^{-1}$ in A. lessonii (Raja et al., 2005), to the most Mg-rich test with $\sim 200 \mathrm{mmol} \mathrm{mol}^{-1}$ of, for example, Amphisorus hemprichii or Neorotalia calcar (Raja et al., 2005).

All these Foraminifera test $\mathrm{Mg} / \mathrm{Ca}$ compositions can now be explained as contribution of two processes, the primary process being TMT, which supplies most of the $\mathrm{Ca}$ for the test and fractionates strongly against $\mathrm{Mg}$, and in the absence of another source of cations would result in $\mathrm{Mg} / \mathrm{Ca}$ ratios similar to those of the coccolithophores. However, in contrast with the coccolithophores, the Foraminifera have at least two mechanisms by which unfractionated cations from the adjacent seawater can enter the site of calcification. As discussed above, such passive transport (PT) might be achieved by leaks through gaps in the pseudopodial network and/or by the observed vacuolization of seawater. Both mechanisms allow cations to reach the site of calcification in proportions close to those in the adjacent seawater. Figure 3 shows that even very modest contributions of such an unfractionated PT component can substantially increase the $\mathrm{Mg} / \mathrm{Ca}$ ratio of the test. For example, a PT contribution of only about $0.07 \%$ of the total $\mathrm{Ca}$ needed for the test will bring along enough $\mathrm{Mg}$ to account for the $\mathrm{Mg} / \mathrm{Ca}$ ratio of the test in A. tepida. For A. lobifera, a PT contribution of about $1.1 \%$ is enough, and even for the most Mg-rich Foraminifera tests like in 


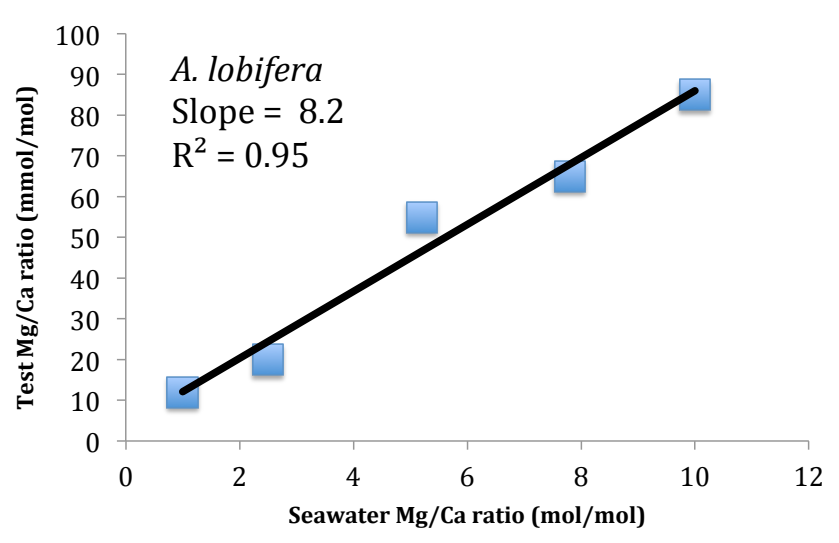

Fig. 4. The relationship between ambient seawater $\mathrm{Mg} / \mathrm{Ca}$ and $\mathrm{Mg} / \mathrm{Ca}$ ratio in the test of $A$. lobifera (average data adopted from Segev and Erez, 2006). For these data, the TMT model predicts a slope of $10 \times \mathrm{PT} \approx 11$, which is within about $25 \%$ of the observed value. (Data for A. lessonii in Segev and Erez (2006) were not included because values for test $\mathrm{Mg} / \mathrm{Ca}$ obtained at normal seawater $\mathrm{Mg} / \mathrm{Ca}$ differ dramatically from those obtained by Raja et al. (2005) for the same species.)

A. hemprichii or $N$. calcar the required PT contribution is only about $4 \%$. These species-specific PT contributions are in very good agreement with the observed vacuolization activity for the species A. aomoriensis and A. lobifera, respectively (this study and Bentov et al., 2009).

Importantly, the model also accounts for the observed $\mathrm{Sr} / \mathrm{Ca}$ ratios in Foraminifera tests, which are comparable to those of the coccolithophore tests. The PT component that is so effective in increasing the $\mathrm{Mg} / \mathrm{Ca}$ ratio, because of the high $\mathrm{Mg} / \mathrm{Ca}$ ratio in seawater, does not affect the test $\mathrm{Sr} / \mathrm{Ca}$ ratio substantially because the seawater $\mathrm{Sr} / \mathrm{Ca}$ ratio is low $(\sim 0.01)$.

Furthermore, our model makes a clear prediction of the $\mathrm{Mg} / \mathrm{Ca}$ ratio of tests formed in seawater with different $\mathrm{Mg} / \mathrm{Ca}$ ratios. This prediction can serve as a test of its validity. Our model predicts that, under constant environmental conditions, the $\mathrm{Mg} / \mathrm{Ca}$ ratio of the test in a given Foraminifera species will be a linear function of the seawater atomic (i.e., $\mathrm{mol} \mathrm{mol}^{-1}$ ) ratio, $\left(\frac{\mathrm{Mg}}{\mathrm{Ca}}\right)_{\mathrm{SW}}$, with a slope dictated by the species-specific PT contribution (in \%), according to the following equation (for details see Appendix):

$$
\left(\frac{\mathrm{Mg}}{\mathrm{Ca}}\right)_{\text {test }}\left(\mathrm{mmol} \mathrm{mmol}^{-1}\right) \approx 10 \times \mathrm{PT} \times\left(\frac{\mathrm{Mg}}{\mathrm{Ca}}\right)_{\mathrm{SW}} .
$$

Note that such a linear relationship is only expected to hold within a reasonable range of $\left(\frac{\mathrm{Mg}}{\mathrm{Ca}}\right)_{\mathrm{SW}}$ that will allow the Foraminifera to form chambers in the absence of stress. We tentatively suggest that the linear relationship predicted by our model should hold for $\left(\frac{\mathrm{Mg}}{\mathrm{Ca}}\right)_{\mathrm{SW}}$ ratios in the range between 1 and $10 \mathrm{~mol} \mathrm{~mol}^{-1}$. As shown in Fig. 4, the model is in good agreement with data for A. lobifera from Segev and Erez (2006). At least two additional data sets currently exist (manuscripts in preparation) that fit the model predictions very well (A. Funcke, personal communication, 2013, and D. Evans, personal communication, 2013).

In contrast, in the endocytosis model a similar linear relationship would require that the hypothetical Mg-removal mechanism be capable of removing systematically and precisely the same fraction of $\mathrm{Mg}$ atoms initially present in each vesicle (which have different size and therefore contain a different number of $\mathrm{Mg}$ atoms) despite changing seawater $\mathrm{Mg} / \mathrm{Ca}$ ratios. This seems highly improbable. Culture experiments in which Foraminifera are grown under different seawater $\mathrm{Mg} / \mathrm{Ca}$ ratios will therefore be capable of clearly distinguishing the two models.

\section{Summary}

In summary, the TMT + PT model presented here is the first to explain the $\mathrm{Mg} / \mathrm{Ca}$ ratios measured in Foraminifera quantitatively. Furthermore, it has several clear advantages compared to existing (qualitative) models: (i) it avoids the problems of vesicle volume and turnover timescale as well as hypothetical selective removal of $\mathrm{Mg}$ required by vacuolization models (Bentov and Erez, 2006). (ii) It does not require $\mathrm{Ca}$ storage. (iii) It accounts for the full range of Foraminifera test trace-element compositions, as a species-specific result of different PT (e.g., vacuolization) contributions to the test, which also allow FITC-D to reach the site of biomineralization. (iv) It makes a clear prediction of Foraminifera test $\mathrm{Mg} / \mathrm{Ca}$ ratios in response to variations in seawater $\mathrm{Mg} / \mathrm{Ca}$. (v) Finally, the TMT model offers a qualitative hypothesis to explain the generally observed positive correlation between seawater temperature and test $\mathrm{Mg} / \mathrm{Ca}$. Metabolism, hence vacuolization (to feed on microorganisms), can be expected to increase with increasing temperature. This process might be what makes the $\mathrm{Mg} / \mathrm{Ca}$ ratio of foraminiferal tests recorders of ocean temperature and global climate change.

\section{Appendix A}

\section{Sample collection and culturing}

Surface sediment was collected at the Wadden Sea (near Dorum, Germany) at low tide. After collection, macrofauna was removed by sieving with a $630 \mu \mathrm{m}$ screen, and the sediment was kept in plastic containers at $10^{\circ} \mathrm{C}$. Living Ammonia aomoriensis (showing yellow colored cytoplasm) were picked and then isolated individually in a 24-well plate containing North Sea water (NSW) and incubated at $25^{\circ} \mathrm{C}$. Three times a week the medium was replaced and the Foraminifera were fed with living Dunaliella salina. After asexual reproduction (ca. $10 \%$ of all individuals), juveniles consisting of a proloculus (first chamber) with ca. $40 \mu \mathrm{m}$ diameter were isolated 
Table A1. Experimental details and results of the fluorescent labeling experiments.

\begin{tabular}{|c|c|c|c|c|c|c|c|}
\hline ID & Prior/during/after & $\begin{array}{l}\text { Incubation } \\
\text { time (h) }\end{array}$ & $\begin{array}{r}\text { Size foram } \\
(\mu \mathrm{m})\end{array}$ & $\begin{array}{l}\text { Volume foram } \\
\qquad\left(\mu \mathrm{m}^{3}\right)\end{array}$ & $\begin{array}{r}\text { No. of } \\
\text { vesicles }\end{array}$ & $\begin{array}{r}\text { Tot. vol. of } \\
\text { vesicles }\left(\mu \mathrm{m}^{3}\right)\end{array}$ & $\begin{array}{r}\text { Vesicle vol./ } \\
\text { foram vol }\end{array}$ \\
\hline c2 & $\mathrm{p}$ & 3.5 & 119 & 882347 & 21 & 355 & 0.000403 \\
\hline $\mathrm{d} 3$ & $\mathrm{p}$ & 4.25 & & & & & \\
\hline $\mathrm{c} 1$ & $\mathrm{p}$ & 5.5 & & & & & \\
\hline $\mathrm{c} 4$ & $\mathrm{p}$ & 4 & 160 & 2163212 & 9 & 56 & 0.000026 \\
\hline c3 & $\mathrm{p}$ & 4 & 341 & 1726464 & 18 & 2741 & 0.001588 \\
\hline b4 & $\mathrm{p}$ & 3 & 204 & 4477286 & 24 & 179 & 0.000040 \\
\hline $\mathrm{d} 2$ & $\mathrm{p}$ & 3 & & & & & \\
\hline b6 & $\mathrm{p}$ & 8 & 97 & 482620 & 3 & 1 & 0.000002 \\
\hline $\mathrm{c} 4$ & $\mathrm{~d}$ & 1.25 & & & & & \\
\hline d6 & $\mathrm{d}$ & 4.5 & & & & & \\
\hline $\mathrm{c} 5$ & $\mathrm{~d}$ & 2 & & & & & \\
\hline b4 & $\mathrm{a}$ & 1 & & & & & \\
\hline b6 & $\mathrm{a}$ & 1.75 & & & & & \\
\hline $\mathrm{a} 2$ & $\mathrm{a}$ & 1.5 & & & & & \\
\hline $\mathrm{d} 2$ & $\mathrm{a}$ & 1.75 & & & & & \\
\hline b3 & $\mathrm{a}$ & 1 & 125 & 1045899 & 5 & 405 & 0.000387 \\
\hline $\mathrm{c} 1$ & $\mathrm{a}$ & 8 & 160 & 2150698 & 15 & 211 & 0.000098 \\
\hline
\end{tabular}

Table A2. Values for $\mathrm{Sr} / \mathrm{Ca}$ and $\mathrm{Mg} / \mathrm{Ca}$ for seawater, coccolithophores and different Foraminifera species reported in the literature.

\begin{tabular}{lrrr}
\hline & $\begin{array}{r}\mathrm{Sr} / \mathrm{Ca} \\
\mathrm{mmol} \mathrm{mol}^{-1} \\
\text { (average) }^{-1}\end{array}$ & $\begin{array}{r}\mathrm{Mg} / \mathrm{Ca} \\
\mathrm{mmol} \mathrm{mol}^{-1} \\
\text { (average) }\end{array}$ & Ref. \\
\hline $\begin{array}{l}\text { Seawater } \\
\text { Coccolithophores }\end{array}$ & 8.8 & 5139 & $(1)$ \\
(average) & 3.5 & 0.1 & $(2)$ \\
A. tepida & 1.3 & 2 & $(4)$ \\
A. lobifera & - & 59 & $(5)$ \\
A. lessonii & 1.67 & 77 & $(3)$ \\
A. hemprichii & 1.81 & 238 & $(3)$ \\
N. calcar & 1.98 & 236 & $(3)$ \\
\hline
\end{tabular}

(1) Pilson, M. E. Q.: An introduction to the chemistry of the sea,

Prentice-Hall, New Jersey, 431 pp., 1998.

(2) Blanco-Ameijeiras, S., Lebrato, M., Stoll, H. M., Iglesias-Rodriguez, M.

Méndez-Vicente, D. A., Sett, S., Müller, M. N., Oschlies, A., and Schulz, K.

G.: Removal of organic magnesium in coccolithophore calcite, Geochimica et Cosmochimica Acta, 89, 226 pp., 2012.

(3) Raja, R., Saraswati, P. K., Rogers, K., and Iwao, K.: Magnesium and strontium compositions of recent symbiont-bearing benthic foraminifera, Mar. Micropaleontol., 58, 31 pp., 2005.

(4) Dissard, D., Nehrke, G., Reichart, G. J., and Bijma, J.: The impact of salinity on the $\mathrm{Mg} / \mathrm{Ca}$ and $\mathrm{Sr} / \mathrm{Ca}$ ratio in the benthic foraminifera Ammonia tepida: Results from culture experiments, Geochimica et Cosmochimica Acta, 74, 928 pp., 2010.

(5) Segev, E. and Erez, J.: Effect of $\mathrm{Mg} / \mathrm{Ca}$ ratio in seawater on shell composition in shallow benthic foraminifera, Geochem. Geophys. Geosyst., 7, Q02P09, doi:10.1029/2005GC000969, 2006.

in Petri dishes until they had grown ca. 5-9 chambers and incubated in fluorescent dye for various periods.

\section{A1 Fluorescent labeling}

A. aomoriensis clones were transferred individually to 24well plates containing NSW the night before the experiment and fed in order to enhance chamber formation. Prior to the experiment NSW containing FITC-D (fluorescin isothiocyanate-dextran; Sigma-Aldrich, MW = 10000) was added to the wells containing the Foraminifera (final concentration $1 \mathrm{~g} \mathrm{~L}^{-1}$ ) FITC-D. Due to its high molecular weight, FITC-D is non-membrane-permeable and consequently allows visualization of the vacuolization process. The incubation time varied between 1 and $8 \mathrm{~h}$.

In order to analyze the correlation between chamber formation and seawater endocytosis, we examined the vesicle formation of Foraminifera at three different stages: prior, during and after chamber formation.

To investigate the vesicle formation prior to chamber formation, randomly picked Foraminifera were incubated in FITC-D. As soon as the beginning of a new chamber formation event was detected (formation of protective cyst, extrusion of cytoplasm bulge), the foraminifer was washed and the amount of fluorescent vesicles inside the animal was determined using confocal laser scanning microscopy (CLSM, Leica, DM IRBE).

In the second set of experiments, Foraminifera that had just started chamber formation were incubated in FITC-D for the period of the chamber formation event $(\sim 3 \mathrm{~h})$. When the new chamber was finished (as indicated by the extension of pseudopodia), the Foraminifera were washed and analyzed by means of CLSM.

In the third set of experiments, Foraminifera were incubated in FITC-D directly after the completion of a new 
chamber for a time span of 1-2 $\mathrm{h}$, then washed and analyzed by means of CLSM.

Washing: At the end of the incubation period, the seawater containing FITC-D was carefully removed with a pipette in order to disturb the Foraminifera as little as possible. Fresh seawater was added and the rinsing process repeated 3 times to ensure that all FITC-D was removed.

CLSM: The well plates were placed under a CLSM. The $488 \mathrm{~nm}$ laser band of a $\mathrm{Kr} / \mathrm{Ar}$ laser was used to excite the fluorescent probe, and emission wavelengths between 500 and $560 \mathrm{~nm}$ were recorded. Individuals were scanned directly after the washing step and thereafter in regular intervals (about every hour) to follow the fate of the vesicles. Since FITC-D is sensitive to photo-bleaching, the specimens were kept in the dark in between scans.

Quantification of vesicles: Vesicles were described by means of their size (area, volume) using the LCS Lite Software (Leica). Volumes of vesicles were calculated from the area $(\mathrm{A}=$ area, $\mathrm{d}=$ diameter, $\mathrm{V}=$ volume) using the following equations:

$\mathrm{d}=2 \sqrt{\frac{\mathrm{A}}{\pi}}$

$\mathrm{V}_{\text {sphere }}=\frac{1}{6} \pi \mathrm{d}^{3}$

The following assumptions were made:

- circular shape of all vesicles,

- circular shape of Foraminifera,

- even though vesicles might have shown different fluorescence intensities, they were treated as being of equal intensities, because intensities are attenuated when vesicles are out of the confocal plane.

\section{A2 NanoSIMS imaging of ${ }^{44} \mathrm{Ca} /{ }^{40} \mathrm{Ca}$ in the test}

Analyses were carried out with the Cameca NanoSIMS ion microprobe at the Muséum National d'Histoire Naturelle in Paris on polished and gold-coated cross-sections of of tests embedded in an epoxy resin. A primary beam of $\mathrm{O}^{-}$(ca. $20 \mathrm{pA}$ ) delivered to the sample surface produced secondary ions of ${ }^{40} \mathrm{Ca}^{+}$and ${ }^{44} \mathrm{Ca}^{+}$that were transmitted to the mass spectrometer and detected simultaneously in electron multipliers at a mass resolving power of $\sim 6500$. At this massresolving power, any potentially problematic mass interferences are resolved. Individual images were obtained by rastering across a pre-sputtered surface (to remove the gold coating and establish sputtering equilibrium) with a lateral resolution of the primary beam of about $0.3 \mu \mathrm{m}$ and comparable pixel size (images of $128 \times 128$ pixels on a $40 \times 40 \mu \mathrm{m}^{2}$ surface area).

Figure A1a and $b$ show examples of individual NanoSIMS maps in ${ }^{40} \mathrm{Ca}$ and ${ }^{44} \mathrm{Ca}$, respectively, from the Foraminifera
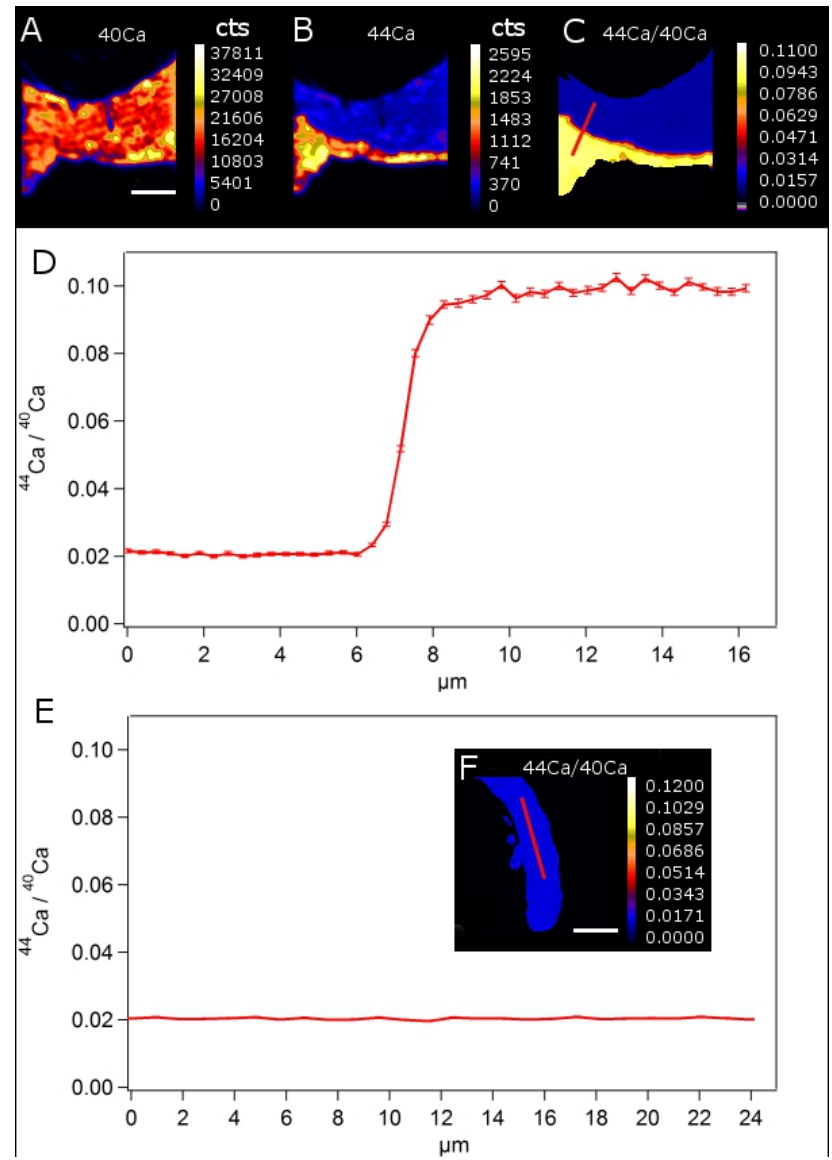

Fig. A1. (A) and (B) show examples of individual NanoSIMS maps in ${ }^{40} \mathrm{Ca}$ and ${ }^{44} \mathrm{Ca}$, respectively, from the Foraminifera exhibited in Fig. 2d. The ${ }^{40} \mathrm{Ca}$ map is flat, whereas the ${ }^{44} \mathrm{Ca}$ map shows clear enrichment in the part of the test formed during the labeling experiment. (C) shows the ${ }^{44} \mathrm{Ca} /{ }^{40} \mathrm{Ca}$ ratio map in which blue color signifies a normal ${ }^{44} \mathrm{Ca} /{ }^{40} \mathrm{Ca}$ ratio of 0.02 and yellowish color signifies a ${ }^{44} \mathrm{Ca} /{ }^{40} \mathrm{Ca}$ ratio enhanced by a factor of 5 (i.e., a ratio of $0.10)$ due to the ${ }^{44} \mathrm{Ca}$ enrichment of the seawater during chamber formation. (D) shows the ${ }^{44} \mathrm{Ca} /{ }^{40} \mathrm{Ca}$ profile extracted from the ${ }^{44} \mathrm{Ca} /{ }^{40} \mathrm{Ca}$ ratio map in $(\mathbf{C})$. (E) shows a ${ }^{44} \mathrm{Ca} /{ }^{40} \mathrm{Ca}$ profile extracted from the Foraminifera test exhibited in Fig. $2 \mathrm{~b}$ (cf. 2F) demonstrating that the blue color signifies a natural ${ }^{44} \mathrm{Ca} /{ }^{40} \mathrm{Ca}$ ratio. Scale bars are $10 \mathrm{~m}$.

exhibited in Fig. 2d. The ${ }^{40} \mathrm{Ca}$ map is flat, whereas the ${ }^{44} \mathrm{Ca}$ map shows clear enrichment in the part of the test formed during the labeling experiment. Figure A1c shows the ${ }^{44} \mathrm{Ca} /{ }^{40} \mathrm{Ca}$ ratio map in which blue color signifies a normal ${ }^{44} \mathrm{Ca} /{ }^{40} \mathrm{Ca}$ ratio of 0.02 and yellowish color signifies a ${ }^{44} \mathrm{Ca} /{ }^{40} \mathrm{Ca}$ ratio enhanced by a factor of 5 (i.e., a ratio of 0.10) due to the ${ }^{44} \mathrm{Ca}$ enrichment of the seawater during chamber formation. Figure A1d shows the ${ }^{44} \mathrm{Ca} /{ }^{40} \mathrm{Ca}$ profile extracted from the ${ }^{44} \mathrm{Ca} /{ }^{40} \mathrm{Ca}$ ratio map in Fig. A1c.

Figure A1e shows a ${ }^{44} \mathrm{Ca} /{ }^{40} \mathrm{Ca}$ profile extracted from the foram test exhibited in Fig. 2 b (cf. Fig. A1f) demonstrating 
that the blue color signifies a natural ${ }^{44} \mathrm{Ca} /{ }^{40} \mathrm{Ca}$ ratio. Scale bars are $10 \mu \mathrm{m}$.

\section{A3 The TMT + PT mixing model}

The low $\mathrm{Mg} / \mathrm{Ca}$ ratios of coccolithophores demonstrate that trans-membrane transport fractionates strongly against $\mathrm{Mg}$. Roughly, for every $10000 \mathrm{Ca}$ atoms only $1 \mathrm{Mg}$ atom reaches the site of calcification.

Let PT be the atomic fraction of $\mathrm{Ca}$ ions transported to the site of calcification via vacuolization. And let $\left(\frac{\mathrm{Mg}}{\mathrm{Ca}}\right)_{\mathrm{SW}}$ be the atomic ratio $\left(\mathrm{mol} \mathrm{mol}^{-1}\right)$ of $\mathrm{Mg}$ and $\mathrm{Ca}$ in seawater.

The atomic $\mathrm{Mg} / \mathrm{Ca}$ ratio of the resulting test is a result of a mixture of contributions from TMT and the PT of seawater and is given by

$\left(\frac{\mathrm{Mg}}{\mathrm{Ca}}\right)_{\text {test }}=\frac{1+10000 \times \mathrm{PT} \times\left(\frac{\mathrm{Mg}}{\mathrm{Ca}}\right)_{\mathrm{SW}}}{10000 \times(1+\mathrm{PT})}$,

which can be approximated by

$$
\left(\frac{\mathrm{Mg}}{\mathrm{Ca}}\right)_{\text {test }} \approx \frac{\mathrm{PT}}{1+\mathrm{PT}} \times\left(\frac{\mathrm{Mg}}{\mathrm{Ca}}\right)_{\mathrm{SW}} \approx \mathrm{PT} \times\left(\frac{\mathrm{Mg}}{\mathrm{Ca}}\right)_{\mathrm{SW}} .
$$

Expressing the $\mathrm{Mg} / \mathrm{Ca}$ ratio of the test in $\mathrm{mmol} \mathrm{mol}^{-1}$ and converting the PT contribution from atomic to percent fraction (as used in the main text), one gets

$$
\left(\frac{\mathrm{Mg}}{\mathrm{Ca}}\right)_{\text {test }}\left(\mathrm{mmol} \mathrm{mmol}^{-1}\right) \approx 10 \times \mathrm{PT}(\%) \times\left(\frac{\mathrm{Mg}}{\mathrm{Ca}}\right)_{\mathrm{SW}} .
$$

Acknowledgements. This work was supported by the European Commission through grant 211384 (EU FP7 "EPOCA"), the German Federal Ministry of Education and Research (BMBF, FKZ 03F0608, "BIOACID"), European Research Council Advanced Grant 246749 (BIOCARB) to A. Meibom, European Research Council Advanced Grant 267931 (NEWLOG), and the European Community's 7th Framework Programme under grant agreement 265103 (Project MedSeA). N. Keul is the beneficiary of a doctoral grant from the AXA Research Fund.

Edited by: A. Shemesh

\section{References}

Allen, G. J. and Sanders, D.: Two Voltage-Gated, Calcium Release Channels Coreside in the Vacuolar Membrane of Broad Bean Guard Cells, The Plant Cell Online, 6, 685-694, 1994.

Bentov, S. and Erez, J.: Impact of biomineralization processes on the $\mathrm{Mg}$ content of foraminiferal shells: A biological perspective, Geochem. Geophys. Geosys., 7, 1-11, doi:10.1029/2005GC001015, 2006.

Bentov, S., Brownlee, C., and Erez, J.: The role of seawater endocytosis in the biomineralization process in calcareous foraminifera, Proc. Natl. Acad. Sci., 106, 21500-21504, 2009.
Blanco-Ameijeiras, S., Lebrato, M., Stoll, H. M., IglesiasRodriguez, M. D., Méndez-Vicente, A., Sett, S., Müller, M. N., Oschlies, A., and Schulz, K. G.: Removal of organic magnesium in coccolithophore calcite, Geochimica et Cosmochimica Acta, 89, 226-239, doi:10.1016/j.gca.2012.04.043, 2012.

de Nooijer, L. J., Langer, G., Nehrke, G., and Bijma, J.: Physiological controls on seawater uptake and calcification in the benthic foraminifer Ammonia tepida, Biogeosciences, 6, 26692675, doi:10.5194/bg-6-2669-2009, 2009.

Dissard, D., Nehrke, G., Reichart, G. J., and Bijma, J.: The impact of salinity on the $\mathrm{Mg} / \mathrm{Ca}$ and $\mathrm{Sr} / \mathrm{Ca}$ ratio in the benthic foraminifera Ammonia tepida: Results from culture experiments, Geochim. Cosmochim. Acta, 74, 928-940, 2010.

Elderfield, H., Bertram, C. J., and Erez, J.: A biomineralization model for the incorporation of trace elements into foraminiferal calcium carbonate, Earth. Planet. Sci. Lett., 142, 409-423, 1996.

Elderfield, H. and Ganssen, G.: Past temperature and [delta] 180 of surface ocean waters inferred from foraminiferal $\mathrm{Mg} / \mathrm{Ca}$ ratios, Nature, 405, 442-445, 2000.

Erez, J.: The Source of Ions for Biomineralization in Foraminifera and Their Implications for Paleoceanographic Proxies, Rev. Mineral. Geochem., 54, 115-149, 2003.

Gussone, N., Langer, G., Thoms, S., Nehrke, G., Eisenhauer, A., Riebesell, U., and Wefer, G.: Cellular calcium pathways and isotope fractionation in Emiliania huxleyi, Geology, 34, 625-628, 2006.

Hayward, B. W., Holzmann, M., Grenfell, H. R., Pawlowski, J., and Triggs, C. M.: Morphological distinction of molecular types in Ammonia - towards a taxonomic revision of the world's most commonly misidentified foraminifera, Mar. Micropaleontol., 50, 237-271, 2004.

Kiessling, W., Aberhan, M., and Villier, L.: Phanerozoic trends in skeletal mineralogy driven by mass extinctions, Nature Geosci., 1, 527-530, 2008.

Langer, G., Gussone, N., Nehrke, G., Riebesell, U., Eisenhauer, A., Kuhnert, H., Rost, B., Trimborn, S., and Thoms, S.: Coccolith strontium to calcium ratios in Emiliania huxleyi: The dependence on seawater strontium and calcium concentrations, Limno. Oceanogr., 51, 310-320, 2006.

Langer, G., Nehrke, G., Thoms, S., and Stoll, H.: Barium partitioning in coccoliths of Emiliania huxleyi, Geochim. Cosmochim. Acta, 73, 2899-2906, 2009.

Martin, R. E.: Cyclic and secular variation in microfossil biomineralization: clues to the biogeochemical evolution of Phanerozoic oceans, Glob. Planet. Change, 11, 1-23, doi:10.1016/09218181(94)00011-2, 1995.

Pilson, M. E. Q.: An introduction to the chemistry of the sea, Prentice-Hall, New Jersey, 431 pp., 1998.

Raja, R., Saraswati, P. K., Rogers, K., and Iwao, K.: Magnesium and strontium compositions of recent symbiontbearing benthic foraminifera, Mar. Micropal., 58, 31-44, doi:10.1016/j.marmicro.2005.08.001, 2005.

Schallreuter, R. E. L.: Calcareous foraminifera from the Ordovician of Baltoscandia, J. Micropal., 2, 1-6, 1983.

Schweizer, M., Polovodova, I., Nikulina, A., and Schönfeld, J.: Molecular identification of Ammonia and Elphidium species (Foraminifera, Rotaliida) from the Kiel Fjord (SW Baltic Sea) with rDNA sequences, Helgol. Mar. Res., 65, 1-10, doi:10.1007/s10152-010-0194-3, 2011. 
Segev, E. and Erez, J.: Effect of $\mathrm{Mg} / \mathrm{Ca}$ ratio in seawater on shell composition in shallow benthic foraminifera, Geochem. Geophys. Geosyst., 7, Q02P09, doi:10.1029/2005gc000969, 2006.
Urey, H. C., Lowenstam, H. A., Eppstein, S., and McKinney, C. R.: Measurement of paleotemperatures and temperatures of the Upper Cretaceous of England, Denmark and the Southeastern United States, Geol. Soc. America, 62, 399-416, 1951. 